\title{
Poly(Lactic Acid) (PLA)/Acrylonitrile Butadiene Styrene (ABS) with Graphene Nanoplatelet (GNP) Nanocomposites
}

\author{
Mohd Bijarimi ${ }^{1{ }^{*}}$, Noor Shahadah ${ }^{1}$, Azizan Ramli ${ }^{1}$, Said Nurdin ${ }^{1}$, Waleed Alhadadi ${ }^{1}$, \\ Muhammad Zakir Muzakkar², and Jamiluddin Jaafar ${ }^{3}$ \\ ${ }^{1}$ Faculty of Chemical and Natural Resources Engineering, Universiti Malaysia Pahang, \\ Lebuhraya Tun Razak 26300, Gambang, Pahang, Malaysia \\ ${ }^{2}$ Department of Chemistry, Faculty of Mathematics and Science, Universitas Haluoleo, Kendari 93232, Indonesia \\ ${ }^{3}$ Faculty of Mechanical Engineering, Universiti Malaysia Pahang, 26600 Pekan, Pahang, Malaysia
}

\begin{abstract}
${ }^{*}$ Corresponding author:
Abstract: A melt blending of poly(lactic acid) (PLA)/acrylonitrile-butadiene-styrene tel: $+609-5492918$

email:bijarimi@ump.edu.my (ABS) with 30:70 PLA:ABS was prepared by a twin screw extruder with a die of $25 \mathrm{~mm}$ width and $0.5 \mathrm{~mm}$ thickness with various loadings of graphene (0-1.0 wt.\%). The PLA/ABS blends were evaluated for mechanical, morphology, thermal properties and Received: August 3, 2018

Accepted: December 13, 2018 interaction of the components in the blend system. Results show the incorporation of graphene nanoplatelet (GNP) improved the tensile and modulus properties. Nevertheless,

DOI: $10.22146 / \mathrm{ijc} .40880$ it was observed that at higher GNP loadings, i.e., 0.6-1.0 wt.\%, both tensile and modulus properties showed a decreasing trend. It was also found that the thermal stability for the blend slightly improved when graphene presence in the blend.
\end{abstract}

Keywords: ABS; PLA; melt blending; nanocomposites

\section{- INTRODUCTION}

Poly(lactic acid) (PLA) is a biodegradable linear aliphatic thermoplastic polyester derived from agricultural products which are renewable resources such as sugarcane, potato, and corn. PLA has huge potential to substitute conventional petroleum-based polymer due to its inherent strength, biocompatibility and low toxicity [1-2]. Unfortunately, the application of PLA in engineering plastic is limited because of low crystallinity, low thermal deformation, and brittleness [3]. Hence, blending PLA with other polymer is the most practical and economical method to improve the elongation and toughness properties of the PLA [3-4].

Acrylonitrile-butadiene-styrene (ABS) used to toughen PLA due to its excellent properties such as high toughness, rigidity, good thermal stability and resistance to chemical and environmental attack. It is also costeffective, durable and low coefficient of thermal expansion, hence it is easy to mold product with good dimensional stability. These advantages have enabled the
ABS to be used in 3D printing material [5-6]. It is known that ABS has been used to toughen the brittleness of PLA, but the modulus and strength properties reduced significantly [7]. In order to overcome these drawbacks, many types of research used nanofillers that act as a reinforcing agent in the binary or ternary blends of polymers [4,8-9]. For example, Desa et al. reported that they had produced a multiwalled carbon nanotubes nanocomposite with improved tensile strength and stiffness as compared to neat PLA [10]. In another study, Weng et al. introduced montmorillonite into ABS matrix and improved mechanical properties and thermal properties of Fused Deposition Modeling (FDM) 3D printed samples [11]. A recent study, Seddik et al. found that immiscibility of PLA and polycaprolactone (PCL) could be overcome by the use of organomontmorillonite (OMMT) nanoclay and graphene in the blend [12].

Graphene is widely used as a filler in polymer blend for applications ranging from electronics, medical and automotive sectors. It has a high Young's modulus, tensile strength, aspect ratio, and thermal conductivity. Polymer 
nanocomposites based on graphene is still extensively investigated by both academia and industry due to high levels of stiffness and strength [13-18]. The objectives of this study were to prepare a binary blend of PLA/ABS with the incorporation of graphene nanoplatelet from $0.2-1.0 \mathrm{wt} . \%$ and then characterized it for mechanical, thermal, chemical and morphological properties.

\section{- EXPERIMENTAL SECTION}

\section{Materials}

Poly(lactic acid) NatureWorks Ingeo ${ }^{\mathrm{TM}}$ Biopolymer 3251 thermoplastic resin was used in this study. It has a density of $1.24 \mathrm{~g} / \mathrm{cm}^{3}$ and a melting temperature between $155-170{ }^{\circ} \mathrm{C}$. Acrylonitrile-butadiene-styrene (ABS) was purchased from Toray Plastics (Malaysia) Sdn Bhd. Graphene Nanoplatelets (GNP) grade $M$ with a thickness of $6-8 \mathrm{~nm}$ and a surface area of $120-150 \mathrm{~m}^{2} / \mathrm{g}$ was purchased from XG Sciences, Inc. The composition of PLA/ABS was fixed at 30:70 by wt.\%.

\section{Procedure}

PLA, ABS pellets were dried in an oven at $45{ }^{\circ} \mathrm{C}$ respectively for $12 \mathrm{~h}$ prior to compound mixing. Melt blending of PLA/ABS was carried out via a Haake twinscrew extruder. The temperature profiles used during compounding was between $180-210{ }^{\circ} \mathrm{C}$. The screw rotation speed of the extruder was kept constant $50 \mathrm{rpm}$. PLA/ABS/GNP extrudates were allowed to cool at ambient temperature. Samples for testing were molded to form a thin film ( $40 \mathrm{~mm}$ wide $\times 40 \mathrm{~mm}$ long x $3 \mathrm{~mm}$ thickness). Stress-strain properties characterization was carried out at room temperature according to ASTM D638 using a Universal Testing Machine with a crosshead speed of $50 \mathrm{~mm} \mathrm{~min}^{-1}$. Microscopy observation was performed on the tensile fractured specimen. The chemical changes after blending were recorded using a Spectrum 400 FT-IR and spectrometer with $4 \mathrm{~cm}^{-1}$ resolution and 10 scans at the $4000-600 \mathrm{~cm}^{-1}$ region. The glass transition temperature and melting temperatures were determined by using a differential scanning calorimetry (DSC) at a scan rate of $20^{\circ} \mathrm{C} / \mathrm{min}$. The thermal decomposition of the nanocomposites was evaluated in a thermogravimetric analyzer from $25^{\circ} \mathrm{C}$ to $600{ }^{\circ} \mathrm{C}$ at a scanning rate of $20^{\circ} \mathrm{C} \mathrm{min}^{-1}$ under nitrogen.

\section{- RESULTS AND DISCUSSION}

Stress-strain properties of PLA/ABS nanocomposites are shown in Table 1. The incorporation of graphene nanoplatelet changed the stress-strain properties as compared to pristine PLA/ABS binary blend. It was found that tensile strength for PLA/ABS with $0.2 \mathrm{wt} . \%$ of graphene nanoplatelet increased from 7.58 to $9.78 \mathrm{MPa}$. A similar trend was observed when the GNP content was increased further to $0.6 \mathrm{wt} . \%$. However, further addition of GNP after 0.6 wt.\% decreased the tensile strength in the PLA/ABS/GNP nanocomposites. As for Young's modulus, only a small increase was noted when the GNP was increased from 0.2 to $1.0 \mathrm{wt} . \%$. This phenomenon can be explained that the addition of GNP could significantly increase the mechanical properties due to the large aspect ratio of the graphene sheets in the ABS matrix. According to the work of Jiajie Liang et al. the mechanical performance of graphene/PVA nanocomposites was significantly increased when compared with the pristine PVA matrix [19]. Similar observation on the enhancement of tensile strength and modulus due to a small amount of graphene was also reported by Kuilla [20].

Table 1. Summary for tensile strength, Young's modulus and elongation at break for PLA/ABS graphene nanocomposites

\begin{tabular}{cccc}
\hline $\begin{array}{c}\text { Graphene content } \\
(\%)\end{array}$ & $\begin{array}{c}\text { Tensile strength } \\
(\mathrm{MPa})\end{array}$ & $\begin{array}{c}\text { Young's modulus } \\
(\mathrm{GPa})\end{array}$ & $\begin{array}{c}\text { Elongation at break } \\
(\%)\end{array}$ \\
\hline 0 & 7.58 & 1.20 & 1.27 \\
0.2 & 9.78 & 1.29 & 1.28 \\
0.4 & 10.99 & 1.37 & 1.66 \\
0.6 & 10.24 & 1.30 & 1.41 \\
0.8 & 9.67 & 1.29 & 1.27 \\
1.0 & 9.39 & 1.29 & 1.24 \\
\hline
\end{tabular}

Mohd Bijarimi et al. 
The SEM images in Fig. 1 shows the magnified of the fractured surface of PLA/ABS blend and PLA/ABS blend with graphene nanocomposite from a tensile test. The morphology observation has shown that the addition of graphene into ABS/PLA blend improved their mechanical properties. It is worth noting that there are two phases visible in Fig. 1(a) which indicates the PLA/ABS blend is immiscible and have low interfacial adhesion between PLA/ABS immiscible phases [21]. On the other hand, Fig. 1(b) and (c) showed less droplet and voids in the continuous matrix when graphene loading increased from 0.2 to $0.4 \mathrm{wt} . \%$. Graphene content in PLA/ABS blend contributed to the homogeneousness of the matrix, as the graphene content increase, PLA/ABS blend become more homogenous, thus increase the tensile modulus. However, the homogeneity reaches its maximum at $0.4 \mathrm{wt} . \%$ as the trend of tensile strength and tensile modulus drops. The increment in tensile strength and modulus could be attributed by the much higher modulus of GNP in the matrix that carries more loads of the overall nanocomposite. This can be explained by the transmission electron microscopy (TEM) images as depicted in Fig. 2 where a comparison of PLA/ABS and $\mathrm{PLA} / \mathrm{ABS} / \mathrm{GNP}$ at $0.4 \mathrm{wt} . \%$ was made. It is apparent that the presence of graphene nanosheets between the presence of graphene nanosheets in the PLA/ABS nanocomposites that are thought to be responsible for the enhancement of tensile and modulus. Nevertheless, the GNP in the PLA/ABS tends to agglomerate at higher loadings, i.e. above $0.4 \mathrm{wt} \% \mathrm{~A}$ similar trend was also reported in the previous work, i.e. when graphene loading in PVA matrix reaches its threshold limit, the mechanical properties and the morphology show a significant declination, generally because of the aggregation of graphene [22].

The glass transition temperature $\left(\mathrm{T}_{\mathrm{g}}\right)$, crystallization temperature $\left(\mathrm{T}_{\mathrm{c}}\right)$ and melting temperature $\left(\mathrm{T}_{\mathrm{m}}\right)$ were determined from DSC analysis. Fig. 3 shows the

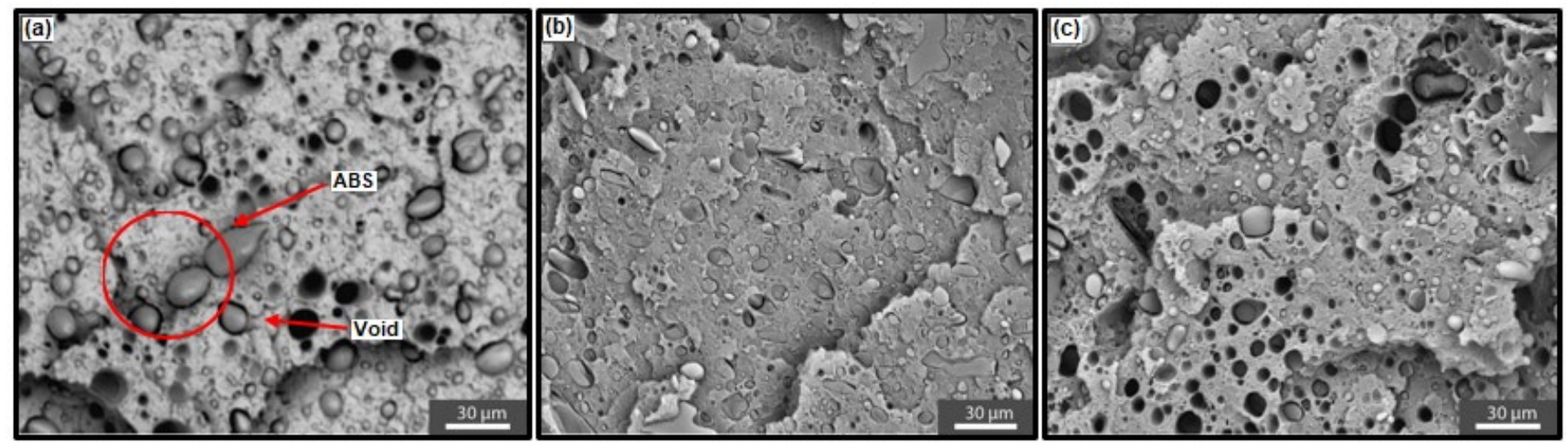

Fig 1. SEM Images of (a) PLA/ABS blend and PLA/ABS with graphene nanocomposite of (b) 0.4 GNP and (c) 0.8 GNP

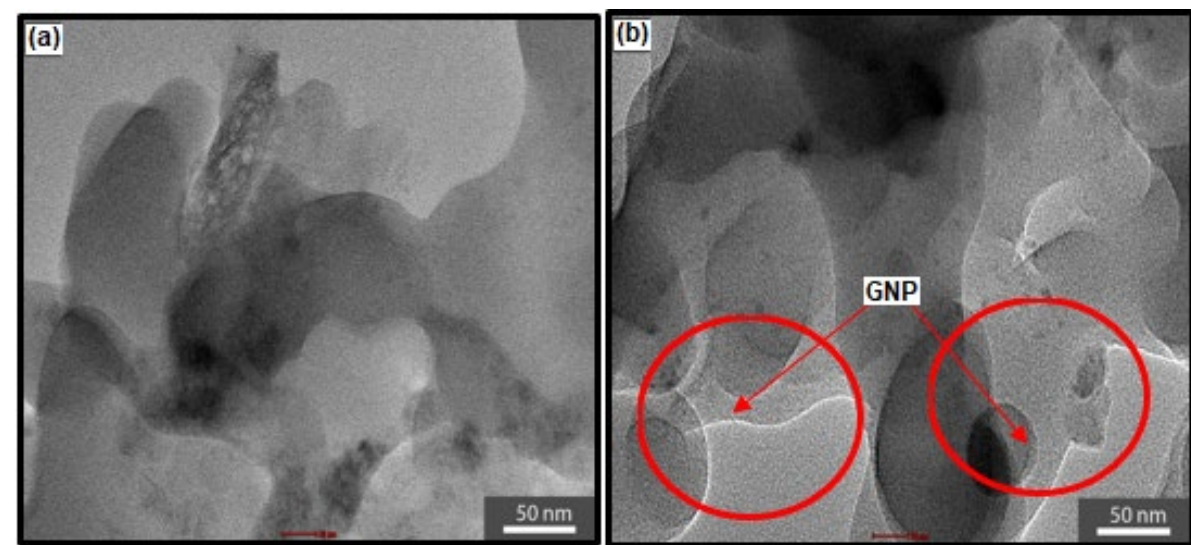

Fig 2. TEM images of (a) PLA/ABS blend and (b) PLA/ABS with graphene nanocomposite of 0.4 GNP 


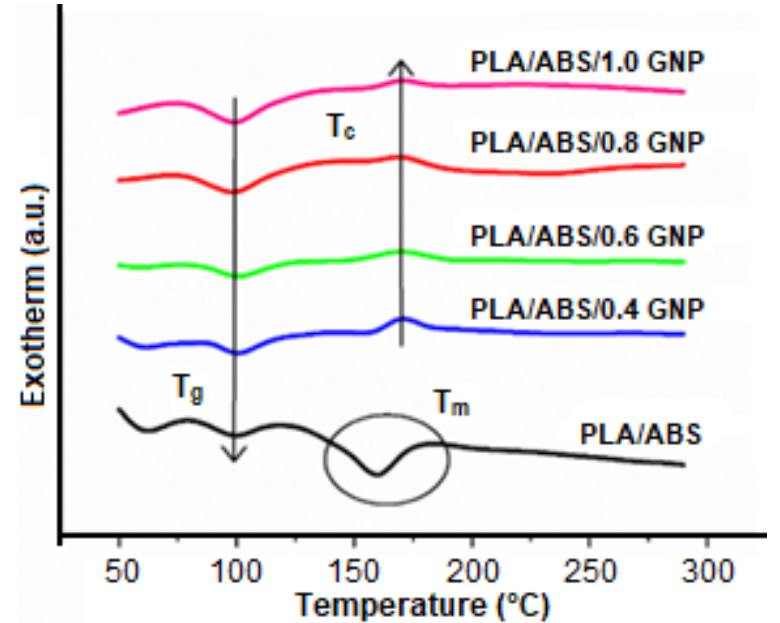

Fig 3. DSC curves of PLA/ABS and PLA/ABS nanocomposite

DSC thermograms for PLA/ABS and nanocomposite with the glass and melting transition regions. From the DSC plot, the glass transition temperatures of PLA/ABS were found to be at $70^{\circ} \mathrm{C}$ but gradually shifted to $110{ }^{\circ} \mathrm{C}$ when the graphene content increased to $1 \mathrm{wt} . \%$. This can be explained due to the fact that the presence of graphene in the PLA/ABS blend hindered the molecular movement that resulted in an increase in $\mathrm{T}_{\mathrm{g}}$. A similar observation was reported by Liang and co-workers when they found that the $\mathrm{T}_{\mathrm{g}}$ of PVA/graphene nanocomposite at $0.7 \mathrm{wt} . \%$ of graphene oxide loading was higher at $3.3^{\circ} \mathrm{C}$ than the pure PVA matrix [19].

Fig. 4 shows the degradation temperatures for PLA/ABS and nanocomposites. It was observed that the
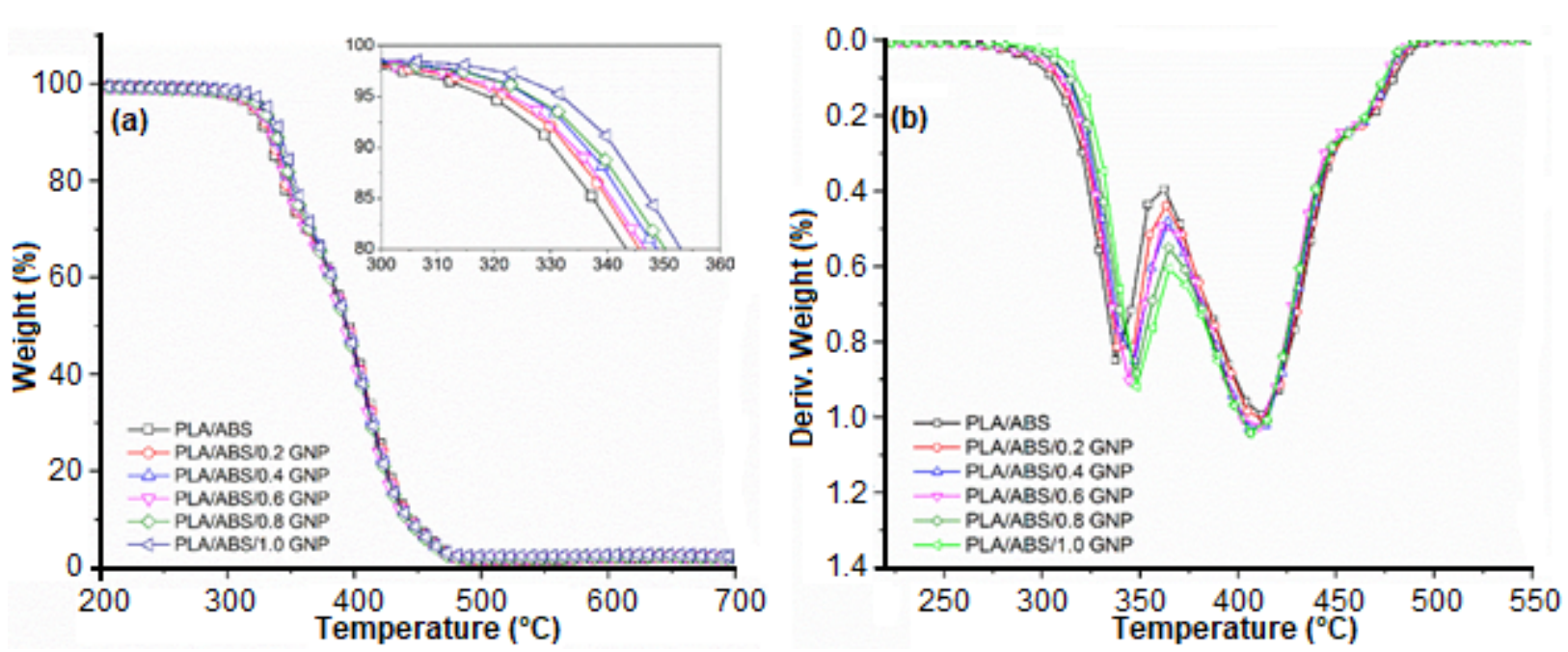

Fig 4. (a) TGA curves and (B) DTG curves of PLA/ABS and PLA/ABS nanocomposite incorporation of graphene in PLA/ABS matrix slightly improved the thermal stability of the blend as evidenced from the TGA plots. Initial decomposition temperature (defined by the temperature at $5 \%$ mass loss) for the blend with GNP changed slightly to higher temperature range than blend without GNP as shown in Fig. 4(a). This can be explained due to the fact that the presence of GNP as a superior insulator [11] and thermal barrier [12] for PLA/ABS matrix during decomposition, hence improved the PLA/ABS blend thermal properties. In the derivative thermogravimetric (DTG) curve, maximum degradation temperature for all blends can be seen in Fig. 4(b); where there are two peaks in the DTG curves which indicate the PLA and ABS degraded individually due to the immiscible blend of the two polymers.

Fig. 5 shows FTIR spectra of pure ABS, pure PLA, PLA/ABS blend and PLA/ABS blend with graphene nanocomposite. A strong and sharp peak in the dashed box (a) at wavenumbers $870-660 \mathrm{~cm}^{-1}$ can be observed at neat $\mathrm{ABS}$ spectrum represent $\mathrm{C}-\mathrm{H}$ bond for alkyl and aromatic group. There is also a peak at that range wavenumbers on PLA/ABS with and without graphene content, indicates that the ABS component did not have any significant role in this blend [23]. As can be seen in Fig. 5, dashed box (c) shows a peak at $1760-1700 \mathrm{~cm}^{-1}$ which indicate the existence of aldehyde/ketone bond $(\mathrm{C}=\mathrm{O})$ and dashed box (b) at $1300-1050 \mathrm{~cm}^{-1}$ that resemble $\mathrm{C}-\mathrm{O}$ bond on PLA and PLA/ABS. Based on these observations, the PLA/ABS and PLA/ABS/GNP at 


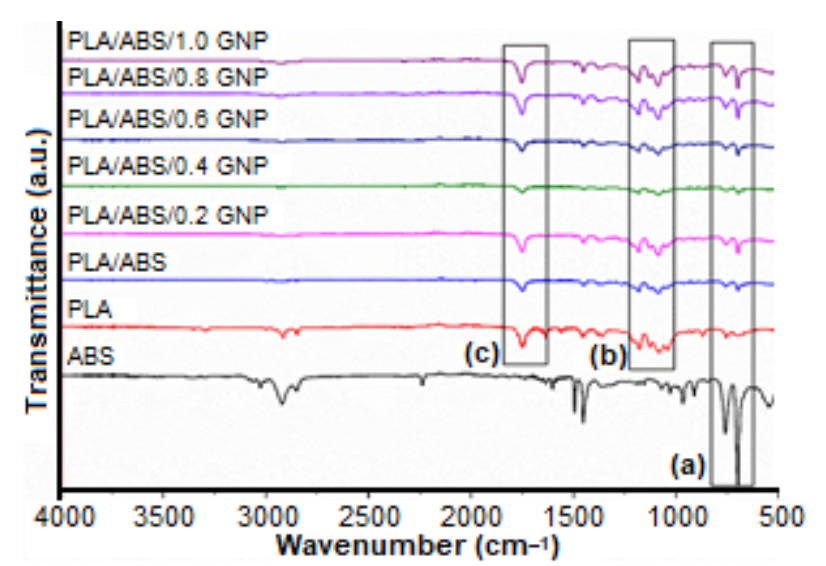

Fig 5. Comparison of FTIR spectra of pure ABS, pure PLA, PLA/ABS and PLA/ABS with nanocomposite

various compositions did not show any significant chemical interaction.

\section{- CONCLUSION}

PLA/ABS graphene nanocomposite was prepared by melt blending and characterized for mechanical, chemical, thermal and morphological properties. The PLA/ABS graphene nanocomposites at $0.4 \mathrm{wt} . \%$ GNP loading has shown the highest tensile strength property. The initial degradation temperature and glass transition temperatures shifted to a higher temperature in the presence of graphene as compared to pristine PLA/ABS blend.

\section{- ACKNOWLEDGMENTS}

The authors wish to acknowledge Universiti Malaysia Pahang (UMP) for the financial assistance provided under the internal research grants (RDU160336 and RDU180351).

\section{- REFERENCES}

[1] Mat Desa, M.S.Z., Hassan, A., Arsad, A., and Mohamad, N.N.B., 2014, Mechanical properties of poly(lactic acid)/multiwalled carbon nanotubes nanocomposites, Mater. Res. Innovations, 18 (Suppl. 6), 14-17.

[2] Bijarimi, M., Ahmad, S., and Alam, A.K.M.M., 2017, Toughening effect of liquid natural rubber on the morphology and thermo-mechanical properties of the poly(lactic acid) ternary blend, Polym. Bull., 74 (8), 3301-3317.
[3] Wu, N., Zhang, H., and Fu, G., 2017, Super-tough poly(lactide) thermoplastic vulcanizates based on modified natural rubber, ACS Sustainable Chem. Eng., 5 (1), 78-84.

[4] Bijarimi, M., Ahmad, S., and Rasid, R., 2013, Mechanical, thermal and morphological properties of poly(lactic acid)/natural rubber nanocomposites, J. Reinf. Plast. Compos., 32 (21), 1656-1667.

[5] Garcia, A., Berthelot, T., Viel, P., Mesnage, A., Jégou, P., Nekelson, F., Roussel, S, and Palacin, S., 2010, $\mathrm{ABS}$ polymer electroless plating through a one-step poly(acrylic acid) covalent grafting, ACS Appl. Mater. Interfaces, 2 (4), 1177-1183.

[6] Olivera, S., Muralidhara, HB., Venkatesh, K., Gopalakrishna, K., and Vivek, C.S., 2016, Plating on acrylonitrile-butadiene-styrene (ABS) plastic: A review, J. Mater. Sci., 51 (8), 3657-3674.

[7] Hamad, K., Kaseem, M., and Deri, F., 2012, Poly(lactic acid)/low density polyethylene polymer blends: Preparation and characterization, Asia-Pac. J. Chem. Eng., 7, S310-S316.

[8] Haniff, M., Bijarimi, M., Zaidi, M.S., and Sahrim, A., 2018, Preparation and characterization of poly(lactic acid) (PLA)/polyoxymethylene (POM) blends, Mater. Sci. Forum, 917, 3-6.

[9] Alam, A.K.M.M., Beg, M.D.H., Yunus, R.M., Bijarimi, M., Mina, M.F., Maria, K.H., and Mieno, T., 2018, Modification of structure and properties of well-dispersed dendrimer coated multi-walled carbon nanotube reinforced polyester nanocomposites, Polym. Test., 68, 116-125.

[10] Mat Desa, M.S.Z., Hassan, A., Arsad, A., and Mohamad, N.N.B., 2016, Influence of rubber content on mechanical, thermal, and morphological behavior of natural rubber toughened poly(lactic acid)-multiwalled carbon nanotube nanocomposites, J. Appl. Polym. Sci., 133 (48), 44344.

[11] Weng, Z., Wang, J., Senthil, T., and Wu, L., 2016, Mechanical and thermal properties of ABS/montmorillonite nanocomposites for fused deposition modeling 3D printing, Mater. Des., 102, 276-283.

[12] Bouakaz, B.S., Habi, A., Grohens, Y., and Pillin, I., 
2017, Organomontmorillonite/graphene-PLA/PCL nanofilled blends: New strategy to enhance the functional properties of PLA/PCL blend, Appl. Clay Sci., 139, 81-91.

[13] Young, R.J., Liu, M., Kinloch, I.A., Li, S., Zhao, X., Vallés, C., and Papageorgiou, D.G., 2018, The mechanics of reinforcement of polymers by graphene nanoplatelets, Compos. Sci. Technol, 154, 110-116.

[14] Li, Z., Chu, J., Yang, C., Hao, S., Bissett, M.A., Kinloch, I.A., and Young, R.J., 2018, Effect of functional groups on the agglomeration of graphene in nanocomposites, Compos. Sci. Technol., 163, 116122.

[15] Papageorgiou, D.G., Kinloch, I.A., and Young, R.J., 2017, Mechanical properties of graphene and graphene-based nanocomposites, Prog. Mater. Sci., 90, 75-127.

[16] Hamid, F.A., Salleh, F.M., Mohamed, N.S., and Adnan, S.B.R.S., 2017, Effect of graphene content on the structure and conductivity of cellulose/graphene composite, Sains Malays., 46 (7),1025-1031.

[17] Norhakim, N., Ahmad, S., Chia, C.H., and Huang, N.M., 2014, Mechanical and thermal properties of graphene oxide filled epoxy nanocomposites, Sains Malays., 43 (4), 603-609.
[18] Abidin, H.E.Z., Hamzah, A.A., and Majlis, B.Y., 2017, Pencirian pertumbuhan lapisan nano grafin di atas elektrod antara digit superkapasitor MEMS, Sains Malays., 46 (7), 1061-1067.

[19] Liang, J., Huang, Yi., Zhang, L., Wang, Y., Ma, Y., Guo, TG., and Chen, Y., 2009, Molecular-level dispersion of graphene into poly(vinyl alcohol) and effective reinforcement of their nanocomposites, Adv. Funct. Mater., 19 (14), 2297-2302.

[20] Kuilla, T., Bhadra, S., Yao, D., Kim, N.H., Bose, S., and Lee, J.H., 2010, Recent advances in graphene based polymer composites, Prog. Polym. Sci., 35 (11), 1350-1375.

[21] Bouakaz, B.S., Pillin, I., Habi, A., and Grohens, Y., 2015, Synergy between fillers in organo montmorillonite/graphene-PLA nanocomposites, Appl. Clay Sci., 116-117, 69-77.

[22] Li, C., Li, Y., She, X., Vongsvivut, J., Li, J., She, F., Gao, W., and Kong, L., 2015, Reinforcement and deformation behaviors of polyvinyl alcohol/ graphene/montmorillonite clay composites, Compos. Sci. Technol., 118, 1-8.

[23] Vadori, R., Misra, M., and Mohanty, A.K., 2016, Sustainable biobased blends from the reactive extrusion of polylactide and acrylonitrile butadiene styrene, J. Appl. Polym. Sci., 133 (45), 43771. 